\title{
Caspase-1 Activity in CD4 T Cells Is Downregulated Following Antiretroviral Therapy for HIV-1 Infection
}

\author{
Rentian Cai,, ${ }^{1, *}$ Li Liu,, ${ }^{1, *}$ Bin Luo, Jiangrong Wang, Jiayin Shen, ${ }^{1}$ Yinzhong Shen, \\ Renfang Zhang, Jun Chen, and Hongzhou Lu, ${ }^{1,3,4}$
}

\begin{abstract}
Both Caspase 1-induced cell death and Caspase 3-induced cell death were reported to be the causes of CD4 ${ }^{+} \mathrm{T}$ cell depletion in HIV infection. We measured by flow cytometry the expression of key proteins associated with pyroptosis (Caspase 1), apoptosis (Caspase 3, Caspase 8, Caspase 9), and immune activation in peripheral T cells. The percentages of $\mathrm{CD}^{+} \mathrm{T}$ cells that expressed Caspase 1 and Caspase 3 were significantly higher in untreated human immunodeficiency virus 1 (HIV-1) patients compared with healthy control (Caspase 1: 19.40\% vs. $4.65 \%, p=.006$; Caspase $3: 12.75 \%$ vs. $4.18 \%, p<.001)$. However, the percentages of Caspase 3 in $\mathrm{CD}^{+} \mathrm{T}$ cells increased significantly, while the percentages of Caspase 1 in $\mathrm{CD}^{+} \mathrm{T}$ cells did not change significantly (Caspase 1: $3.33 \%$ vs. $1.99 \%, p=.821$; Caspase $3: 20.35 \%$ vs $4.74 \%, p<.001$ ). The percentages of HLA-DR ${ }^{+}$ $\mathrm{CD} 38^{+} \mathrm{CD} 8^{+} \mathrm{T}$ cells were positively correlated with those of Caspase $1^{+} \mathrm{CD} 4^{+} \mathrm{T}$ cells, but not with those of Caspase $3^{+} \mathrm{CD}^{+} \mathrm{T}$ cells. After highly active antiretroviral therapy, the percentages of Caspase 1, but not of Caspase 3, -expressing $\mathrm{CD}^{+}{ }^{+} \mathrm{T}$ cells decreased to a level comparable with those of healthy controls (Caspase 1: $6.05 \%$ vs. $4.65 \%, p=.514$; Caspase $3: 9.67 \%$ vs. $4.18 \%, p<.001)$. Our study indicated that $\mathrm{CD}^{+}{ }^{+} \mathrm{T}$ cells experience both pyroptosis and apoptosis, while $\mathrm{CD}^{+} \mathrm{T}$ cells undergo only apoptosis in HIV-1 infection. Pyroptosis, but not apoptosis, in $\mathrm{CD} 4^{+} \mathrm{T}$ cells may be inhibited by effective antiretroviral therapy.
\end{abstract}

Keywords: HIV-1, apoptosis, pyroptosis, anti-retroviral therapy

\section{Introduction}

$\mathbf{T}$ HE MAIN CHARACTERISTIC of human immunodeficiency virus 1 (HIV-1) infection is loss of $\mathrm{CD} 4^{+} \mathrm{T}$ cells; however, the mechanism by which $\mathrm{CD} 4^{+} \mathrm{T}$ cells decrease remains poorly understood. Previous studies suggested that apoptosis may be a key mechanism. ${ }^{1-7}$ However, it was recently reported that most uninfected (bystander) $\mathrm{CD}^{+} \mathrm{T}$ cells were undergoing pyroptosis, while only a small percentage of $\mathrm{CD}^{+}{ }^{+} \mathrm{T}$ cells infected by HIV-1 were undergoing apoptosis. ${ }^{8}$ Pyroptosis and apoptosis are triggered by the cell-signaling molecules, Caspase 1 and Caspase 3, respectively., ${ }^{3,8-10}$

Bystander $\mathrm{CD}^{+} \mathrm{T}$ cells are abortively infected with HIV-1, and short HIV DNA transcripts accumulate in the cytosol. ${ }^{10}$ The DNA sensor, IFI16, detects these viral DNAs and activates Caspase 1 to induced pyroptosis characterized by plasma membrane pore formation and cytoplasmic content extrusion. ${ }^{8,11-14}$

Apoptosis can be initiated through two distinct pathways. In the intrinsic apoptosis pathway, HIV-1 infection leads to the release of cytochrome c from $\mathrm{CD}^{+} \mathrm{T}$ cell mitochondria, leading to activation of Caspase 9 and subsequent Caspase 3 activation. $^{15}$ In the extrinsic pathway, Fas receptor ligand (FasL) combined with Fas triggers Caspase 8 activation, resulting in subsequent Caspase 3 activation. ${ }^{16,17}$ Caspase 3 activated by either pathway induces apoptosis in $\mathrm{CD} 4^{+} \mathrm{T}$ cells. ${ }^{18}$

Apoptosis and pyroptosis may be the two main causes for decreased $\mathrm{CD}^{+}{ }^{\mathrm{T}}$ cells during HIV-1 infection. In this study, we showed that the percentages of $\mathrm{T}$ cells undergoing pyroptosis and apoptosis in HIV-1-infected patients were elevated before combination highly active antiretroviral therapy (HAART) and that Caspase 1 activity, but not Caspase 3, was significantly downregulated following HAART.

\section{Materials and Methods}

\section{Participants}

Forty HIV-1-infected patients naïve to antiretroviral therapy, $40 \mathrm{HIV}$-1-infected patients with undetectable plasma

${ }^{1}$ Department of Infectious Diseases, Shanghai Public Health Clinical Center, Fudan University, Shanghai, China.

${ }^{2}$ Department of Infectious Diseases, Wenzhou Medical College, Wenzhou, China.

${ }^{3}$ Huashan Hospital Affiliated to Fudan University, Shanghai, China.

${ }^{4}$ Medical College of Fudan University, Shanghai, China.

*These authors are co-first authors. 
viral loads for more than 1 year after HAART, and 16 healthy controls were enrolled at Shanghai Public Health Clinical Center, China. HIV-1-infected patients with opportunistic infections, hepatitis B virus (HBV), or hepatitis $\mathrm{C}$ virus (HCV) infection were excluded. Healthy controls with HIV$1, \mathrm{HBV}$, or HCV infection or with medicine were excluded. Ethical approval was granted by the Ethics Committee of Shanghai Public Health Clinical Center (approval number: 2013-K006). Informed written consent was obtained from each volunteer.

\section{Peripheral blood mononuclear cell preparation}

Peripheral blood mononuclear cells (PBMCs) were isolated from $20 \mathrm{~mL}$ heparinized peripheral blood by centrifugation over a Ficoll-Histopaque gradient (Fresenius Kabi, Halden, Norway) and washed with phosphate-buffered saline.

\section{$T$ cell immunophenotyping and intracellular staining}

The following monoclonal antibodies were used for T cell immunophenotyping: CD3-PerCP-Cy5.5 (Biolegend, London, United Kingdom); CD4-BV605, CD8-APC-H7, CD45RA-APC, CD38-PE-Cy7, HLA-DR-PE, Fas-PE-Cy7, FasL-PE, Annexin V-fluorescein isothiocyanate (FITC), 7AAD, IgG2a-PE, and IgG-PE-Cy7 (BD Biosciences, San Jose, CA). The following antibodies were used for intracellular staining: CaspGLOW Fluorescein Active Caspase 3 Staining Kit, CaspGLOW Fluorescein Active Caspase 8 Staining Kit, and CaspGLOW Fluorescein Active Caspase 9 Staining Kit (eBioscience, San Diego, CA); and Caspase 1 (activated P10)-FITC (Bioss, Inc., Woburn, MA).

PBMCs were incubated with antibody cocktails (cocktail 1: CD3, CD4, CD8, CD45RA, CD38, and HLA-DR; cocktail 2: CD3, CD4, CD8, CD45RA, Fas, and FasL; cocktail 3: CD3, CD4, CD8, and CD45RA; cocktail 4: CD3, CD4, CD8, and CD45RA; cocktail 5: CD3, CD4, CD8, and CD45RA; and cocktail 6: CD3, CD4, CD8, CD45RA, IgG2a, and IgG) for $20 \mathrm{~min}$ at $4^{\circ} \mathrm{C}$. After washing, $2 \times 10^{6}$ cells in cocktails 1 , 2, 3, and 4 were further stained with the Active Caspase 3 Staining Kit, Active Caspase 8 Staining Kit, Active Caspase 9 Staining Kit, and Caspase 1 (activated P10)-FITC in accordance with manufacturer instructions to detect Caspase 3, Caspase 8, Caspase 9, and Caspase 1. Cells were then washed and fixed with $1 \%$ formaldehyde and stored at $4^{\circ} \mathrm{C}$. Cells $\left(2 \times 10^{6}\right)$ in cocktail 5 were further stained with Annexin V and 7-AAD, followed by analysis using an LSRFortessa flow cytometer (BD Biosciences). The data were analyzed using FlowJo, version 7.6.4 (FlowJo, LLC, Ashland, OR), and two populations were identified: naive $\left(\mathrm{CD}^{+} \mathrm{CD} 45 \mathrm{RA}^{+}\right.$ and $\left.\mathrm{CD} 84^{+} \mathrm{CD} 45 \mathrm{RA}^{+} \mathrm{Tn}\right)$ and memory $\left(\mathrm{CD} 4^{+} \mathrm{CD} 45 \mathrm{RA}^{-}\right.$and $\left.\mathrm{CD} 4^{+} \mathrm{CD} 45 \mathrm{RA}^{-} \mathrm{Tm}\right)$. Expression of Caspase proteins was determined based on fluorescence minus one, while CD38, HLA-DR, Fas, and FasL expression was determined based on matched isotype controls. The flow cytometry gating strategy for Caspase-1- or Caspase-3-positive cells is shown in Supplementary Figure S1 (Supplementary Data are available online at www.liebertpub.com/aid).

\section{Measurements of HIV-1 RNA in peripheral plasma}

HIV-1 RNA was quantified using the plasma COBAS AmpliPrep/COBAS TaqMan HIV-1 Qualitative Test, ver- sion 2.0 (Roche, Basel, Switzerland), according to manufacturer instructions. The lower limits of detection of the assays were 20 copies $/ \mathrm{mL}$.

\section{Statistical analyses}

The Mann-Whitney $U$ test was used to compare statistical significance between groups. Spearman's rank correlation coefficient was used to assess associations among $\mathrm{CD} 4^{+}$ T cell counts, HIV-1 RNA, and immunologic measurements. Normally distributed data are shown as mean \pm standard deviation, while non-normally distributed data are shown as median (interquartile range). Analyses were two-sided, and $p<.05$ was considered significant. All statistical analyses were performed with SPSS, version 16.0 (SPSS, Inc., Chicago, IL), and GraphPad Prism, version 5.0, software (GraphPad Software, San Diego, CA).

\section{Results}

Patient characteristics are shown in Table 1.

Caspase 1 expression increased in $C D 4^{+} T$ cells, but not in $C D 8^{+} T$ cells, of HIV-1-infected patients

The percentage of $\mathrm{CD} 4^{+} \mathrm{T}$ cells expressing Caspase 1 was significantly higher in untreated HIV-1-infected patients relative to that of healthy controls $[19.40 \%(6.36 \%-27.00 \%)$ vs. $4.65 \%(3.85 \%-6.88 \%) ; p=.006]$. However, the percentage of $\mathrm{CD} 8^{+} \mathrm{T}$ cells expressing Caspase 1 was unchanged in HIV-1-infected patients compared with that observed in healthy controls [3.33\% (1.20\%-6.91\%) vs. $1.99 \%(1.58 \%-$ $5.56 \%) ; p=.821]$ (Fig. 1A, B).

Similar results were observed in both memory $\mathrm{CD}^{+} \mathrm{T}$ cells and naive $\mathrm{CD} 4^{+} \mathrm{T}$ cells and memory $\mathrm{CD} 8^{+} \mathrm{T}$ cells and naive $\mathrm{CD}^{+} \mathrm{T}$ cells (Fig. 1C, D).

\section{Caspase 3 expression increased in both $C D 4^{+}$ and $C D 8^{+} T$ cells in HIV-1-infected patients}

The percentages of $\mathrm{CD}^{+}$and $\mathrm{CD} 8^{+} \mathrm{T}$ cells expressing Caspase 3 were both significantly higher in untreated HIV1-infected patients compared with those of healthy controls $\left[\mathrm{CD} 4^{+}: 12.75 \%(9.11 \%-24.20 \%)\right.$ vs. $4.18 \%(3.42 \%-5.52 \%)$, $p<.001$; CD8: $20.35 \%(11.48 \%-31.25 \%)$ vs. $4.74 \%$ (3.46\%$6.18 \%), p<.001]$ (Fig. 2A, B).

Similar results were observed in both memory $\mathrm{CD}^{+}$ $\mathrm{T}$ cells and naive $\mathrm{CD} 4^{+} \mathrm{T}$ cells and memory $\mathrm{CD} 8^{+} \mathrm{T}$ cells and naive $\mathrm{CD}^{+} \mathrm{T}$ cells (Fig. 2C, D).

\section{No correlations between $C D 4^{+} T$ cell counts, HIV-1} RNA levels, and percentages of Caspase $-1^{+} C D 4^{+}$ $T$ cells and Caspase- $3^{+} C D 4^{+} T$ cells

Among the untreated HIV-1-infected patients, neither $\mathrm{CD}^{+}{ }^{+} \mathrm{T}$ cell count nor HIV-1 RNA levels were correlated with the proportions of $\mathrm{CD}^{+} \mathrm{T}$ cells expressing Caspase 1

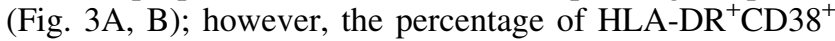
$\mathrm{CD} 8^{+} \mathrm{T}$ cells was positively correlated with $\mathrm{CD} 4^{+} \mathrm{T}$ cells expressing Caspase 1 (Fig. 3C).

Meanwhile, among the untreated HIV-1-infected patients, neither $\mathrm{CD}^{+} \mathrm{T}$ cell counts nor HIV-1 RNA levels were correlated with the proportions of $\mathrm{CD}^{+} \mathrm{T}$ cells expressing Caspase 3 too (Fig. 3D, E). Additionally, percentages of 
Table 1. Clinical Characteristics of Study Groups

\begin{tabular}{|c|c|c|c|}
\hline Characteristics & Untreated $(\mathrm{n}=40)$ & $H A A R T(\mathrm{n}=40)$ & Controls $(\mathrm{n}=16)$ \\
\hline Age median (IQR, years) & $27.5(24-37.8)$ & $38(30.5-50.8)$ & $27(26-31)$ \\
\hline Gender ( $\%$ male $)$ & $39(97.5 \%)$ & $36(90 \%)$ & $10(62.5 \%)$ \\
\hline $\mathrm{CD}^{+} \mathrm{T}$ cells [median (IQR), cells $/ \mu \mathrm{L}$ ] & $424(239-569)$ & 477 (337-589) & N/A \\
\hline $\mathrm{CD}^{+} \mathrm{T}$ cells $[$ median $(\mathrm{IQR})$, cells $/ \mu \mathrm{L}]$ & $760(622-1088)$ & $724(533-1058)$ & N/A \\
\hline CD4/CD8 ratio & $0.51(0.30-0.82)$ & $0.56(0.37-0.99)$ & N/A \\
\hline HAART regimens & & & \\
\hline 2 NRTIs +1 NNRTIs $[n(\%)]$ & NA & $38(95 \%)$ & NA \\
\hline 2 NRTIs +1 PIs $[n(\%)]$ & NA & $2(5 \%)$ & NA \\
\hline Duration of receiving ART, [median (IQR), months] & NA & $35(23.5-53)$ & NA \\
\hline Log10(HIV RNA): (IQR) & $4.56(4.04-4.95)$ & $<1.30$ & NA \\
\hline
\end{tabular}

HAART, highly active antiretroviral therapy; IQR, interquartile range; N/A, not available; NA, not applicable; NNRTIs, non-nucleoside reverse transcriptase inhibitors; NRTIs, nucleoside reverse transcriptase inhibitors; PIs, protease inhibitors.

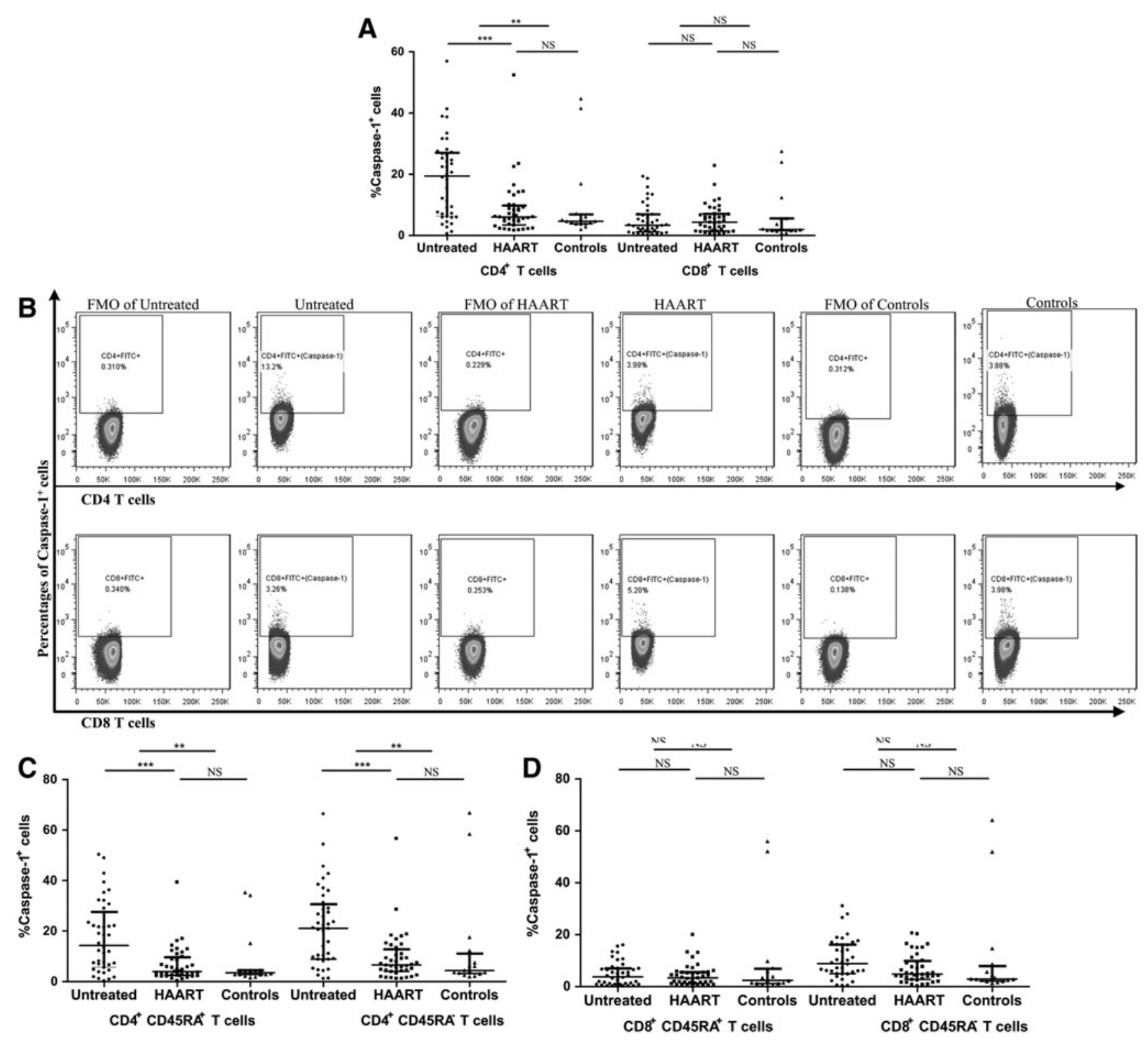

FIG. 1. Percentages of $\mathrm{CD}^{+}$and $\mathrm{CD} 8^{+} \mathrm{T}$ cells expressing Caspase 1 from untreated HIV-1-infected patients, HAART patients, and healthy controls. Caspase 1 expression increased in CD4 ${ }^{+} \mathrm{T}$ cells, but not in $\mathrm{CD} 8^{+} \mathrm{T}$ cells, of HIV-1-infected patients (A) and flow cytometric analysis of PBMCs (B). Percentages of subgroups of CD4 ${ }^{+}(\mathbf{C})$ and $\mathrm{CD}^{+} \mathrm{T}(\mathbf{D})$ cells expressing Caspase $1 . * * p<.01 ; * * * p<.001$. FMO, fluorescence minus one; HAART, highly active antiretroviral therapy; HIV-1, human immunodeficiency virus 1; NS, no statistical significance; PBMCs, peripheral blood mononuclear cells. 

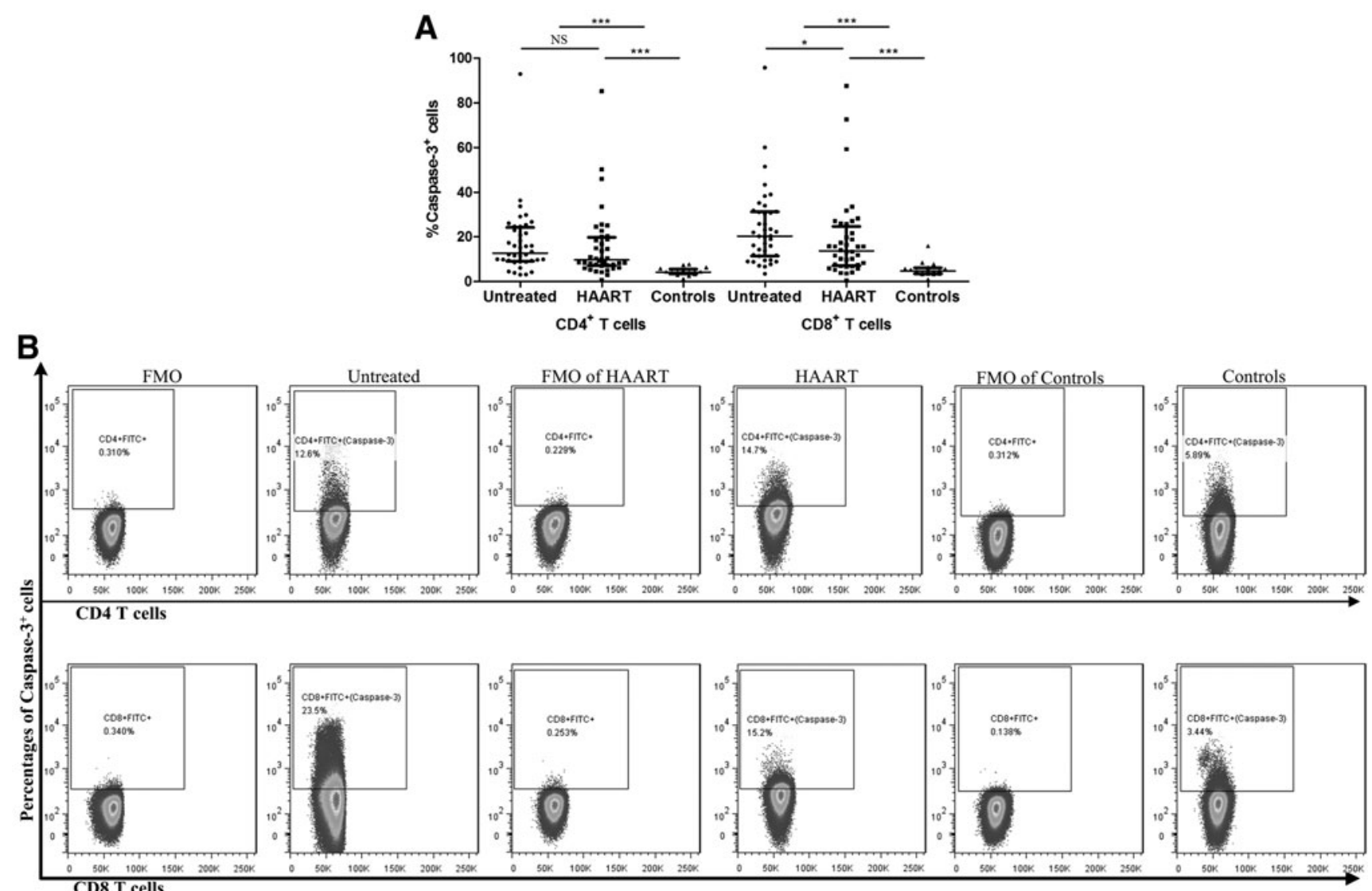

CD8 T cells
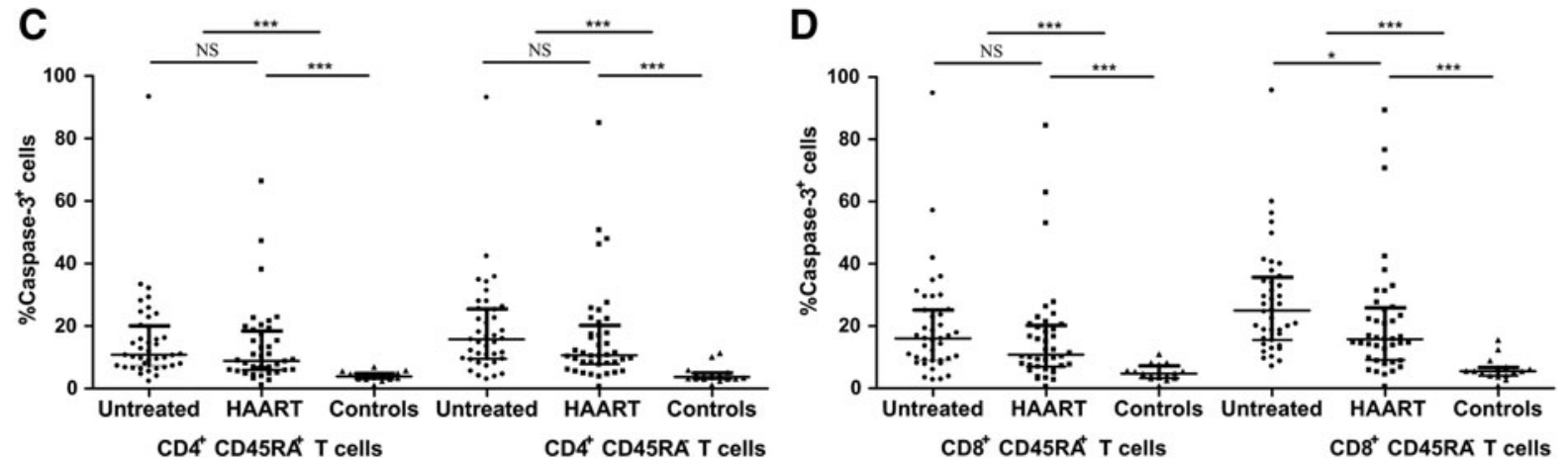

FIG. 2. Percentages of $\mathrm{CD} 4^{+}$and $\mathrm{CD} 8^{+} \mathrm{T}$ cells expressing Caspase 3 from untreated HIV-1-infected patients, HAART patients, and healthy controls. Caspase 3 expression increased in both $\mathrm{CD}^{+}$and $\mathrm{CD} 8^{+} \mathrm{T}$ cells in HIV-1-infected patients (A) and flow cytometric analysis of PBMCs (B). Percentages of subgroups of $\mathrm{CD}^{+}{ }^{+}$(C) and $\mathrm{CD}^{+} \mathrm{T}(\mathbf{D})$ cells expressing Caspase 3. $* p<.05 ; * * * p<.001$; NS, no statistical significance.

HLA-DR ${ }^{+} \mathrm{CD} 38^{+} \mathrm{CD} 8^{+} \mathrm{T}$ cells did not correlate with $\mathrm{CD} 4^{+}$ T cells expressing Caspase 3 (Fig. 3F).

\section{Caspase 1 expression is downregulated in $C D 4^{+}$ $T$ cells in HIV-1-infected patients following HAART}

The percentage of $\mathrm{CD}^{+}{ }^{+} \mathrm{T}$ cells expressing Caspase 1 significantly decreased in the HAART group compared with untreated HIV-1-infected patients [6.05\% (3.43\%-9.78\%) vs. $19.40 \%(6.36 \%-27.00 \%) ; p<.001]$. Furthermore, the percentage of Caspase $1^{+} \mathrm{CD} 4^{+} \mathrm{T}$ cells in the HAART group was comparable with that observed in healthy controls [6.05\% (3.43\%-9.78\%) vs. $4.65 \%(3.85 \%-6.88 \%) ; p=.514]$ (Fig. 1A, B). In contrast to the percentage of $\mathrm{CD}^{+} \mathrm{T}$ cells expressing Caspase 1, the percentage of $\mathrm{CD}^{+}{ }^{+} \mathrm{T}$ cells expressing Caspase 3 in the HAART group was comparable with that observed in untreated HIV-1-infected patients [9.67\% (7.09\%-19.80\%) vs. $12.75 \%(9.11 \%-24.20 \%) ; p=$ .132] and was still higher than that observed in healthy controls [9.67\% (7.09\%-19.80\%) vs. $4.18 \%(3.42 \%-5.52 \%)$; $p<.001$ ] (Fig. 2A, B).

The percentage of $\mathrm{CD}^{+} \mathrm{T}$ cells expressing Caspase $1 \mathrm{did}$ not change significantly in the HAART group compared with untreated patients (Fig. 1A). While the percentage of $\mathrm{CD} 8^{+} \mathrm{T}$ cells expressing Caspase 3 declined significantly in the HAART group, it was still higher than the percentage observed in the healthy controls (Fig. 2A). 

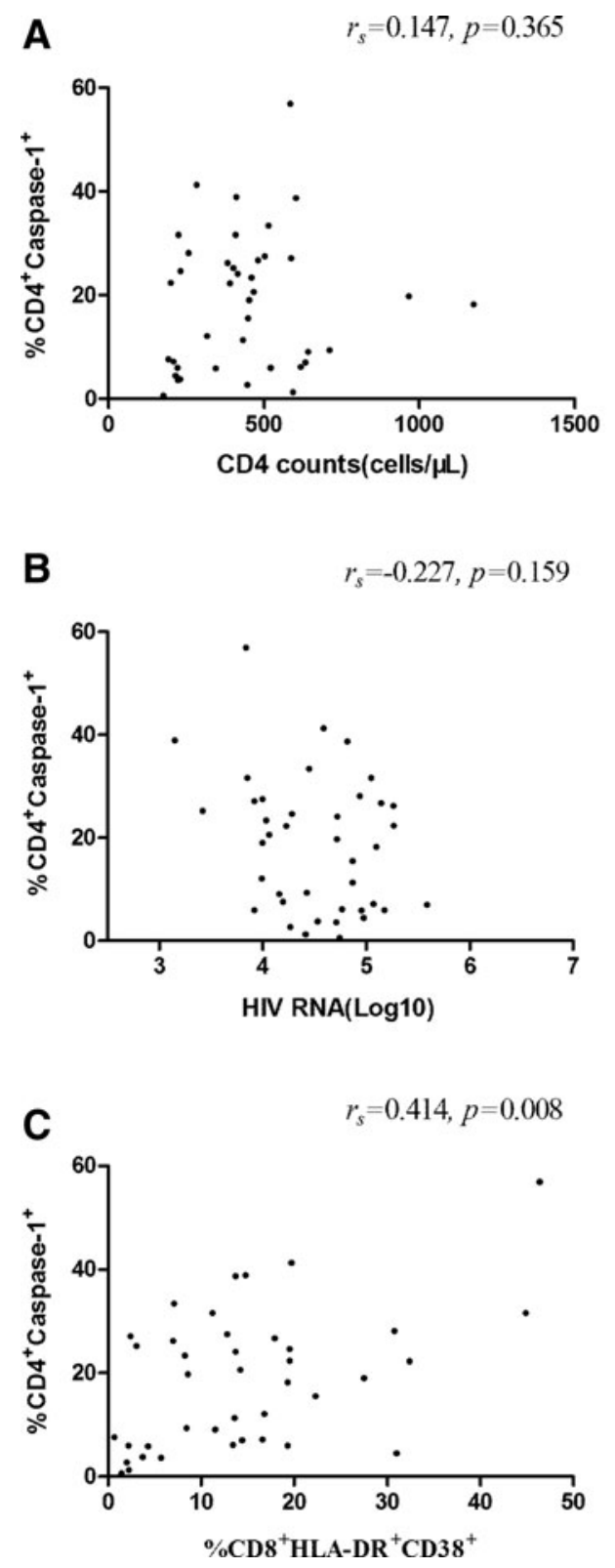
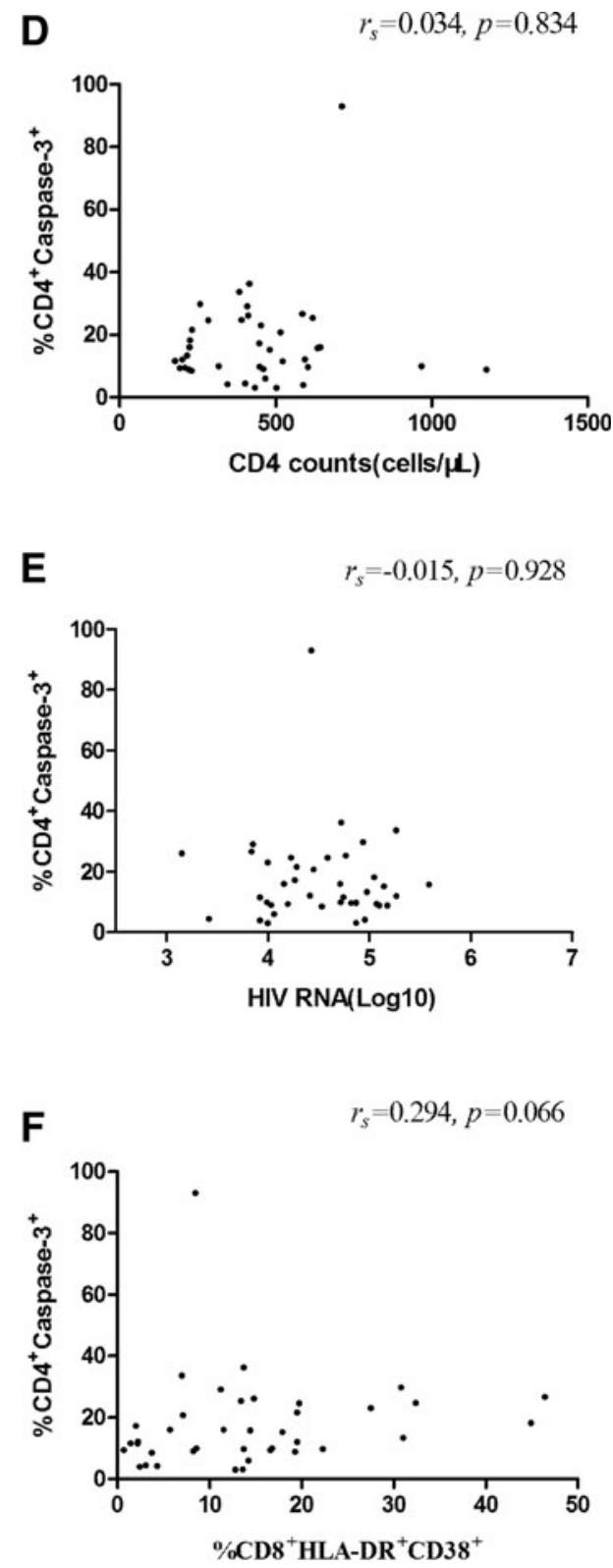

FIG. 3. Correlations between $\mathrm{CD}^{+} \mathrm{T}$ cell counts, HIV-1 RNA levels, and percentages of HLA-DR ${ }^{+} \mathrm{CD} 38^{+}$ $\mathrm{CD}^{+} \mathrm{T}$ cells, Caspase $1^{+} \mathrm{CD} 4^{+} \mathrm{T}$ cells, and Caspase $3^{+} \mathrm{CD}^{+} \mathrm{T}$ cells among the untreated HIV-1-infected patients. Correlations between percentages of Caspase $1^{+} \mathrm{CD}^{+}{ }^{-} \mathrm{T}$ cells and $\mathrm{CD} 4^{+} \mathrm{T}$ cell counts (A), HIV-1 RNA levels (B), and percentages of $\mathrm{HLA}-\mathrm{DR}^{+} \mathrm{CD} 38^{+} \mathrm{CD} 8^{+}$ $\mathrm{T}$ cells $(\mathbf{C})$. Correlations between percentages of Caspase $3^{+} \mathrm{CD}^{+} \mathrm{T}$ cells and $\mathrm{CD} 4^{+}$ T cell counts (D), HIV-1 RNA levels (E), and percentages of $\mathrm{HLA}^{-\mathrm{DR}^{+} \mathrm{CD} 38^{+}} \mathrm{CD} 8^{+}$ $\mathrm{T}$ cells $(\mathbf{F})$.
Furthermore, the percentages of memory and naive CD $4^{+}$ $T$ cells expressing Caspase 1 were significantly lower in the HAART group compared with untreated HIV-1-infected patients and were comparable with the percentages observed in healthy controls (Fig. 1C). However, the percentages of memory and naive $\mathrm{CD} 4^{+} \mathrm{T}$ cells expressing Caspase 3 in the HAART group were comparable with those observed in untreated HIV-1-infected patients and were still higher than those observed in healthy controls (Fig. 2C).

Moreover, the percentages of memory and naïve $\mathrm{CD}^{+} \mathrm{T}$ cells expressing both Caspase 1 and Caspase 3 were similar as those observed in all $\mathrm{CD} 8^{+} \mathrm{T}$ cells. The percentages of the two subgroups of $\mathrm{CD}^{+} \mathrm{T}$ cells expressing Caspase 1 did not change significantly in the HAART group compared with untreated HIV-1-infected patients(Fig. 1D), while the expression levels of Caspase 3 in each of the cell lines declined significantly in the HAART group, but still remained higher than levels in cells from healthy controls (Fig. 2D).
Increased expression of apoptosis-related markers in both $C D 4^{+}$and $C D 8^{+} T$ cells despite HAART

Markers signifying early stages of the extrinsic and intrinsic apoptotic pathways-Caspase 8 and Caspase 9, respectively-in $\mathrm{T}$ cells changed inconsistently following HAART; however, they remained higher than those measured in healthy controls. The percentages of $\mathrm{CD}^{+} \mathrm{T}$ cells expressing Caspase 9, but not Caspase 8, decreased significantly in the HAART group, but were still higher than those observed in healthy controls. Similarly, the percentages of $\mathrm{Fas}^{+}$and $\mathrm{FasL}^{+} \mathrm{CD}^{+} \mathrm{T}$ cells remained elevated in the HAART group. The percentages of HLA-DR ${ }^{+} \mathrm{CD} 38^{+} \mathrm{CD}^{+}$ $T$ cells decreased in the HAART group, but remained higher than those of healthy controls. However, the percentage of $\mathrm{CD}^{+}{ }^{+} \mathrm{LLA}-\mathrm{DR}^{+} \mathrm{CD} 38^{+} \mathrm{T}$ cells in the HAART group decreased to a level comparable with that of healthy controls. The percentages of Annexin $\mathrm{V}^{+} 7-\mathrm{AAD}^{-} \mathrm{CD}^{+} \mathrm{T}$ cells in untreated HIV-1-infected patients were significantly higher 

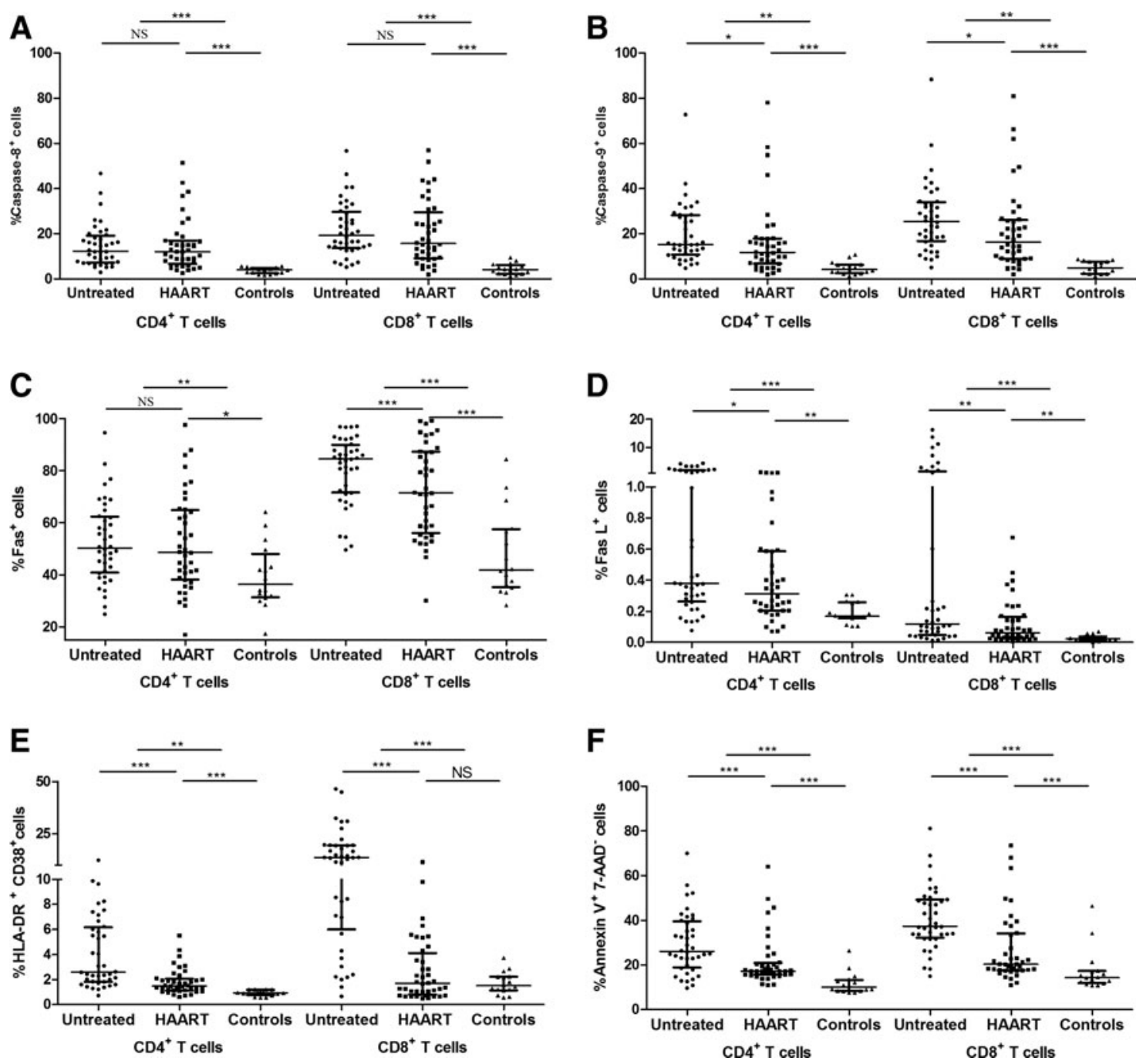

FIG. 4. Increased expression of apoptosis-related markers, Caspase $8^{+}(\mathbf{A})$, Caspase $9^{+}(\mathbf{B}), \mathrm{Fas}^{+}(\mathbf{C}), \mathrm{Fas} \mathrm{L}^{+}(\mathbf{D}), \mathrm{HLA}^{-}$ $\mathrm{DR}^{+} \mathrm{CD} 38^{+}(\mathbf{E})$, Annexin $\mathrm{V}^{+} 7-\mathrm{AAD}^{-}(\mathbf{F})$, in both $\mathrm{CD} 4^{+}$and $\mathrm{CD} 8^{+} \mathrm{T}$ cells despite HAART. $* p<.05 ; * * p<.01 ; * * * p<.001$; NS, no statistical significance.

than that observed in healthy controls; however, even though the percentage decreased in the HAART group, it still remained higher than that of healthy controls (Fig. 4.).

\section{Discussion}

Both pyroptosis and apoptosis were reported to be the main causes of $\mathrm{CD}^{+}{ }^{\mathrm{T}}$ cell depletion during HIV-1 infection. ${ }^{1-8}$ In this study, we reported the impact of HAART on the percentages of $\mathrm{T}$ cells undergoing pyroptosis and apoptosis in HIV-1-infected patients.

Pyroptosis is triggered by Caspase 1 following the initiation of specific cytosolic signals. ${ }^{10,19-22}$ In agreement with this, Doitsh et al. ${ }^{8}$ reported that pyroptosis accounted for $>95 \%$ of resting lymphoid $\mathrm{CD}^{+}{ }^{+} \mathrm{T}$ cell loss. We confirmed that a high proportion of peripheral $\mathrm{CD}^{+} \mathrm{T}$ cells were undergoing pyroptosis, indicating that pyroptosis may be one of the main causes of $\mathrm{CD}^{+} \mathrm{T}$ cell depletion. Meanwhile, the percentages of $\mathrm{CD}^{+} \mathrm{T}$ cells expressing Caspase 1 did not increase in HIV-1-infected patients. One explanation might involve bystander $\mathrm{CD}^{+} \mathrm{T}$ cells being abortively infected by HIV-1, resulting in cytosolic accumulation of short HIV-1
DNA transcripts. ${ }^{10}$ However, $\mathrm{CD}^{+} \mathrm{T}$ cells cannot be infected abortively or completely. This may further explain why $\mathrm{CD}^{+} \mathrm{T}$ cells were depleted, while the number of $\mathrm{CD} 8^{+}$ $\mathrm{T}$ cells remained unchanged in HIV-1-infected patients. Interestingly, the $\mathrm{CD} 4^{+} \mathrm{T}$ cell counts were not correlated with the percentages of $\mathrm{CD} 4^{+} \mathrm{T}$ cells that express Caspase- 1 in the current studies. The most likely explanation of this observation is that pyroptosis is only one of the mechanisms of $\mathrm{CD}^{+} \mathrm{T}$ cell destruction in HIV infection. Direct cytopathic effect of HIV-1 and apoptosis also cause CD $4^{+} \mathrm{T}$ cell death. Decreased thymic output and enhanced migration of $\mathrm{CD}^{+} \mathrm{T}$ cells to lymph nodes further account for the depletion of $\mathrm{CD}^{+} \mathrm{T}$ cell counts. ${ }^{23-25}$

In a previous study, Caspase 1 serum levels were negatively correlated with HIV-1 RNA levels. ${ }^{26}$ A recent study showed that cell-to-cell transmission of HIV-1 was required to trigger pyroptotic death of lymphoid tissue-derived CD4 ${ }^{+}$ T cells, while free HIV-1 particles failed to induce pyroptosis in vitro. ${ }^{22}$ This may explain our result that the percentage of $\mathrm{CD}^{+} \mathrm{T}$ cells expressing Caspase 1 was not correlated with HIV-1 RNA levels. Munoz-Arias et al. reported that the majority of blood-derived $\mathrm{CD}^{+}{ }^{\mathrm{T}}$ cells from $\mathrm{HIV}-1$-infected 
subjects, regardless of HAART, did not exhibit Caspase 1 activation. $^{27}$ In contrast, we observed that HAART inhibited pyroptosis based on the percentage of $\mathrm{CD}^{+} \mathrm{T}$ cells expressing Caspase 1 decreasing to levels comparable with that of healthy controls. Similar to our result, previous studies also showed elevated expression of Caspase 1 in $\mathrm{CD}^{+} \mathrm{T}$ cells both in vivo and in vitro. ${ }^{28-30}$ Therefore, HAART may not directly prevent pyroptotic death of $\mathrm{CD}^{+} \mathrm{T}$ cells by inhibiting HIV-1 replication, but rather by blocking upstream events involved in productive HIV-1 infection in other $\mathrm{CD} 4^{+} \mathrm{T}$ cells.

It was previously reported that pyroptosis links the two signature events in HIV-1 infection: $\mathrm{CD}^{+} \mathrm{T}$ cell depletion and chronic inflammation. ${ }^{8,9}$ In our study, the percentages of both $\mathrm{CD}^{+} \mathrm{T}$ cells and $\mathrm{CD} 8^{+} \mathrm{T}$ cells that express Caspase 1 were positively correlated with levels of the activation markers, HLA-DR and CD38. Following HAART, Caspase 1 expression was inhibited, while immune activation remained high in CD4 T cells. This phenomenon may be due to immune activation being driven by other factors (e.g., microbial translocation) besides persistent HIV-1 infection. ${ }^{31-33}$

Apoptosis was linked to $\mathrm{CD}^{+} \mathrm{T}$ cell loss in HIV-1 infection both in vitro and in vivo. ${ }^{1-7,34-36}$ Our study showed that both the intrinsic and extrinsic apoptotic pathways were activated in HIV-1-infected patients, which were similar to previous reports. $^{34,35,37}$ Therefore, both apoptosis and pyroptosis contributed to $\mathrm{CD}^{+} \mathrm{T}$ cell depletion in HIV-1infected patients. Unlike pyroptosis, apoptotic activity, and specifically that associated with the extrinsic pathway, remained elevated after HAART according to our results. Furthermore, both Fas and FasL, which are triggers of the extrinsic apoptotic pathway, were also highly expressed in $\mathrm{CD}^{+} \mathrm{T}$ cells. This is consistent with previous findings reported from other laboratories. ${ }^{35,38-40}$ This result indicated that apoptosis, but not pyroptosis, may have impeded immune restoration after HAART. Therefore, methods to decrease apoptosis to restore $\mathrm{CD}^{+} \mathrm{T}$ cell counts in patients with impaired immune reconstruction require further investigation.

The main limitation of this study was that we did not investigate $\mathrm{CD}^{+} \mathrm{T}$ cells from different tissues, such as lymph nodes or spleens. Cell-to-cell transmission of HIV-1 was shown to be essential to initiate pyroptotic cell death. ${ }^{22}$ Given that the cells in this study were obtained from peripheral blood where cell contact occurs less frequently compared with that observed in lymphoid tissue, the results from our study could not be expanded to T cells associated with lymph nodes or spleens. Additionally, the cross-sectional nature of this study also impedes causal inferences. Thus, further investigations are still needed.

In conclusion, our study found that the percentages of $\mathrm{CD}^{+} \mathrm{T}$ cells expressing both Caspase 1 and Caspase 3 increased in HIV-1-infected patients, while only the percentage of $\mathrm{CD}^{+} \mathrm{T}$ cells expressing Caspase 3 increased in these patients. Our results suggested that inhibition of Caspase 1, but not Caspase 3, induction of cell death pathways in $\mathrm{CD} 4^{+}$ $\mathrm{T}$ cells could be mediated by effective antiretroviral therapy, which warrants further investigation.

\section{Acknowledgments}

The authors are thankful to all of the HIV-1-infected patients enrolled for this study. This work received grants from the Chinese National Natural Science Foundation (grant no.
81301420 ), the 863 project (SS2014AA021403), and the 12th five-year infectious disease research project (2012ZX10001003 and 2012ZX09303013).

\section{Author Disclosure Statement}

No competing financial interests exist.

\section{References}

1. Fevrier M, Dorgham K, Rebollo A: CD4+ T cell depletion in human immunodeficiency virus (HIV) infection: Role of apoptosis. Viruses 2011;3:586-612.

2. Finkel TH, Tudor-Williams G, Banda NK, et al.: Apoptosis occurs predominantly in bystander cells and not in productively infected cells of HIV- and SIV-infected lymph nodes. Nat Med 1995;1:129-134.

3. Garg H, Mohl J, Joshi A: HIV-1 induced bystander apoptosis. Viruses 2012;4:3020-3043.

4. Grivel JC, Malkevitch N, Margolis L: Human immunodeficiency virus type 1 induces apoptosis in CD4(+) but not in CD8(+) T cells in ex vivo-infected human lymphoid tissue. J Virol 2000;74:8077-8084.

5. Jekle A, Keppler OT, De Clercq E, Schols D, Weinstein M, Goldsmith MA: In vivo evolution of human immunodeficiency virus type 1 toward increased pathogenicity through CXCR4-mediated killing of uninfected CD4 T cells. J Virol 2003;77:5846-5854.

6. Muro-Cacho CA, Pantaleo G, Fauci AS: Analysis of apoptosis in lymph nodes of HIV-infected persons. Intensity of apoptosis correlates with the general state of activation of the lymphoid tissue and not with stage of disease or viral burden. J Immunol 1995; 154:5555-5566.

7. Rosok BI, Brinchmann JE, Stent G, et al.: Correlates of apoptosis of CD4+ and CD8+ T cells in tonsillar tissue in HIV type 1 infection. AIDS Res Hum Retroviruses 1998; 14:1635-1643.

8. Doitsh G, Galloway NL, Geng X, et al.: Cell death by pyroptosis drives CD4 T-cell depletion in HIV-1 infection. Nature 2014;505:509-514.

9. Doitsh G, Cavrois M, Lassen KG, et al.: Abortive HIV infection mediates CD4 T cell depletion and inflammation in human lymphoid tissue. Cell 2010;143:789-801.

10. Monroe KM, Yang Z, Johnson JR, et al.: IFI16 DNA sensor is required for death of lymphoid CD4 T cells abortively infected with HIV. Science 2014;343:428-432.

11. Miao EA, Rajan JV, Aderem A: Caspase-1-induced pyroptotic cell death. Immunol Rev 2011;243:206-214.

12. Miao EA, Leaf IA, Treuting PM, et al:: Caspase-1-induced pyroptosis is an innate immune effector mechanism against intracellular bacteria. Nat Immunol 2010;11:1136-1142.

13. Fink SL, Cookson BT: Apoptosis, pyroptosis, and necrosis: Mechanistic description of dead and dying eukaryotic cells. Infect Immun 2005;73:1907-1916.

14. Lamkanfi M, Dixit VM: Manipulation of host cell death pathways during microbial infections. Cell Host Microbe 2010;8:44-54.

15. Roggero $\mathrm{R}$, Robert-Hebmann $\mathrm{V}$, Harrington $\mathrm{S}$, et al.: Binding of human immunodeficiency virus type 1 gp120 to CXCR4 induces mitochondrial transmembrane depolarization and cytochrome c-mediated apoptosis independently of Fas signaling. J Virol 2001;75:7637-7650.

16. Nie Z, Bren GD, Rizza SA, Badley AD: HIV protease cleavage of procaspase 8 is necessary for death of HIVinfected cells. Open Virol J 2008;2:1-7. 
17. Cummins NW, Jiang W, McGinty J, et al.: Intracellular Casp8p41 content is inversely associated with CD4 T cell count. J Infect Dis 2010;202:386-391.

18. Andersen MH, Becker JC, Straten P: Regulators of apoptosis: Suitable targets for immune therapy of cancer. Nat Rev Drug Discov 2005;4:399-409.

19. Bergsbaken T, Fink SL, den Hartigh AB, Loomis WP, Cookson BT: Coordinated host responses during pyroptosis: Caspase-1-dependent lysosome exocytosis and inflammatory cytokine maturation. J Immunol 2011;187: 2748-2754.

20. Fink SL, Bergsbaken T, Cookson BT: Anthrax lethal toxin and Salmonella elicit the common cell death pathway of caspase-1-dependent pyroptosis via distinct mechanisms. Proc Natl Acad Sci U S A 2008;105:4312-4317.

21. Fink SL, Cookson BT: Caspase-1-dependent pore formation during pyroptosis leads to osmotic lysis of infected host macrophages. Cell Microbiol 2006;8:1812-1825.

22. Galloway NL, Doitsh G, Monroe KM, et al.: Cell-to-cell transmission of HIV-1 is required to trigger pyroptotic death of lymphoid-tissue-derived CD4 T cells. Cell Rep 2015;12:1555-1563.

23. Hayasaka H, Kobayashi D, Yoshimura H, Nakayama EE, Shioda T, Miyasaka M: The HIV-1 Gp120/CXCR4 axis promotes CCR7 ligand-dependent CD4 T cell migration: CCR7 homo- and CCR7/CXCR4 hetero-oligomer formation as a possible mechanism for up-regulation of functional CCR7. PLoS One 2015;10:e0117454.

24. Chen JJ, Huang JC, Shirtliff M, et al.: CD4 lymphocytes in the blood of $\mathrm{HIV}(+)$ individuals migrate rapidly to lymph nodes and bone marrow: Support for homing theory of CD4 cell depletion. J Leukoc Biol 2002;72:271-278.

25. Ho Tsong Fang R, Colantonio AD, Uittenbogaart $\mathrm{CH}$ : The role of the thymus in HIV infection: A 10 year perspective. AIDS 2008;22:171-184.

26. Song J, Jiao Y, Zhang T, et al:: Longitudinal changes in plasma Caspase-1 and Caspase- 3 during the first 2 years of HIV-1 infection in CD4Low and CD4High patient groups. PLoS One 2015;10:e0121011.

27. Munoz-Arias I, Doitsh G, Yang Z, Sowinski S, Ruelas D, Greene WC: Blood-derived CD4 $\mathrm{T}$ cells naturally resist pyroptosis during abortive HIV-1 infection. Cell Host Microbe 2015;18:463-470.

28. Sloand EM, Kumar PN, Kim S, Chaudhuri A, Weichold FF, Young NS: Human immunodeficiency virus type 1 protease inhibitor modulates activation of peripheral blood CD4(+) $\mathrm{T}$ cells and decreases their susceptibility to apoptosis in vitro and in vivo. Blood 1999;94:1021-1027.

29. Petit F, Corbeil J, Lelievre JD, et al.: Role of CD95activated caspase- 1 processing of IL-1beta in TCR-mediated proliferation of HIV-infected CD4(+) T cells. Eur J Immunol 2001;31:3513-3524.

30. Trinite B, Chan CN, Lee CS, Levy DN: HIV-1 Vpr- and reverse transcription-induced apoptosis in resting peripheral blood CD4 $\mathrm{T}$ cells and protection by common gammachain cytokines. J Virol 2015;90:904-916.

31. Brenchley JM, Price DA, Schacker TW, et al.: Microbial translocation is a cause of systemic immune activation in chronic HIV infection. Nat Med 2006;12:1365-1371.

32. Mburu S, Marnewick JL, Abayomi A, Ipp H: Modulation of LPS-induced CD4+ T-cell activation and apoptosis by an- tioxidants in untreated asymptomatic HIV infected participants: An in vitro study. Clin Dev Immunol 2013;2013: 631063.

33. Steele AK, Lee EJ, Manuzak JA, et al.: Microbial exposure alters HIV-1-induced mucosal CD4+ T cell death pathways ex vivo. Retrovirology 2014;11:14.

34. de Oliveira Pinto LM, Lecoeur H, Ledru E, Rapp C, Patey O, Gougeon ML: Lack of control of T cell apoptosis under HAART. Influence of therapy regimen in vivo and in vitro. AIDS 2002;16:329-339.

35. Feuth T, Van Baarle D, Hoepelman AI, Van Erpecum KJ, Siersema PD, Arends JE: Activation of extrinsic apoptosis pathway in HCV monoinfected and HIV-HCV coinfected patients, irrespective of liver disease severity. Apoptosis 2014;19:1128-1135.

36. Peraire J, Miro O, Saumoy M, et al.: HIV-1-infected longterm non-progressors have milder mitochondrial impairment and lower mitochondrially-driven apoptosis in peripheral blood mononuclear cells than typical progressors. Curr HIV Res 2007;5:467-473.

37. Chen J, Benlahrech A, Kelleher P, Patterson S: Increased activity of extrinsic and intrinsic apoptosis pathways in different mononuclear cell types in HIV type 1-infected patients regardless of whether they are depleted in disease. AIDS Res Hum Retroviruses 2013;29:709-717.

38. Bohler T, Wintergerst U, Linde R, Belohradsky BH, Debatin KM: CD95 (APO-1/Fas) expression on naive CD4(+) $\mathrm{T}$ cells increases with disease progression in HIV-infected children and adolescents: Effect of highly active antiretroviral therapy (HAART). Pediatr Res 2001;49:101-110.

39. Dyrhol-Riise AM, Stent G, Rosok BI, Voltersvik P, Olofsson J, Asjo B: The Fas/FasL system and T cell apoptosis in HIV-1-infected lymphoid tissue during highly active antiretroviral therapy. Clin Immunol 2001;101:169179.

40. Mitra D, Steiner M, Lynch DH, Staiano-Coico L, Laurence J: HIV-1 upregulates Fas ligand expression in CD4+ T cells in vitro and in vivo: Association with Fas-mediated apoptosis and modulation by aurintricarboxylic acid. Immunology 1996;87:581-585.

Address correspondence to: Jun Chen

Department of Infectious Diseases Shanghai Public Health Clinical Center Fudan University 2901 Caolang Road Shanghai 201508

China

E-mail: qtchenjun@163.com

Hongzhou $\mathrm{Lu}$

Department of Infectious Diseases Shanghai Public Health Clinical Center Fudan University

2901 Caolang Road Shanghai 201508

China

E-mail: luhongzhou@fudan.edu.cn 